\title{
Prevalence of Cardiac Arrhythmias During and After Pregnancy in Women with Chagas' Disease without Apparent Heart Disease
}

\author{
Renato Enrique Sologuren Achá, Marco Túlio Oliveira Rezende, \\ Rimmel Amador Guzmán Heredia, Aguinaldo Coelho da Silva, Elmiro Santos Rezende, \\ Cleber Augusto Oliveira Souza
}

Uberlândia, MG - Brazil

\begin{abstract}
Objective - To evaluate cardiac arrhythmias during and after pregnancy in women with Chagas' disease without apparent heart disease using dynamic electrocardiography.
\end{abstract}

Methods - Twenty pregnant women with Chagas'disease without apparent heart disease aged 19 to 42 years $(26.96 \pm 3.6)$ and a control group of 20 non-chagasic pregnant patients aged 16 to 34 years $(22.5 \pm 4.8)$. The patients were submitted to passive hemagglutination and indirect immunofluorescence for the detection of Trypanosomacruzi evaluation, and electrocardiography, echocardiography and 24-h dynamic electrocardiography.

Results - Supraventricular premature depolarizations were observed in 18 (90\%) patients and ventricular premature depolarization in 11 (55\%) patients of both groups during pregnancy. After delivery, supraventricular premature depolarizations were present in $13(60 \%)$ chagasic patients and in $16(89.4 \%)$ control patients $(P \unlhd) .05)$. Ventricular premature depolarization were observed in 9 (45\%) chagasic patients and $11(57.8 \%)$ control patients.

Conclusion - The prevalence of ventricular premature depolarization was similar for the chagasic and control groups during and after pregnancy. The incidence of supraventricular premature depolarizations was similar in the two groups during pregnancy, while after delivery a predominance was observed in the control group compared to the chagasic group.

Key words: Chagas'disease, pregnancy, arrhythmia

Hospital de Clínicas da Universidade Federal de Uberlândia

Correspondência: Renato E. S. Achá - Rua Guaicurus, 270 - 38408-394 Uberlândia, MG-E-mail: solo@triang.com.br
The presence of arrhythmias as well as palpitations, dizziness, presyncope and, eventually, syncope ${ }^{1}$ are events known to occur during pregnancy and are the main reason for the consultation of a cardiologist ${ }^{2}$. Palpitations are related to premature depolarization and/or benign tachyarrhythmias, which are well tolerated from a clinical point of view. However, patients with underlying heart disease and significant left ventricular dysfunction are more susceptible to malignant arrhythmias, which are poorly tolerated and may place the pregnant woman's life at risk due to sudden death ${ }^{2}$. An increase in the incidence of cardiac arrhythmias during pregnancy, including ventricular tachycardia, has been reported in patients with and without heart disease ${ }^{3,4}$.

Many young, healthy women present supraventricular and ventricular premature depolarizations with and without symptoms. Sobotka et $\mathrm{al}^{5}$, studying 50 non-pregnant women without apparent heart disease by 24 -h dynamic electrocardiography, found isolated (supraventricular or ventricular) premature depolarizationss in $44(88 \%)$ of the patients.

The expression "Chagas' disease without apparent heart disease" refers to patients who present positive serology for Chagas' disease and who have a normal electrocardiogram and chest X-ray, but who cannot be assigned to the so-called indeterminate form of Chagas' disease since they were not submitted to radiologic analysis of the digestive tract $^{6}$.

Studies in the literature on cardiac rhythm disturbances in pregnant patients with Chagas' disease are scarce. This fact led us to determine the prevalence of cardiac arrhythmias in pregnant women with Chagas' disease without apparent heart disease.

\section{Methods}

Twenty pregnant women with Chagas' disease without apparent heart disease aged 19 to 42 years $(26.96 \pm 3.6)$, 
seen at the Heart Disease and Pregnancy Outpatient Clinic of the University Hospital, Universidade Federal de Uberlândia (HC-UFU), were studied. All patients were initially submitted to clinical evaluation and then classified according to the criteria established by the New York Heart Association (NYHA). For the diagnosis of chagasic infection two serologic tests for the detection of Trypanosoma cruzi (passive hemagglutination and indirect immunofluorescence) were carried out. The patients were submitted to conventional 12lead electrocardiography using a simultaneous 6-channel Ecafix apparatus, with the exam being considered to be normal when the sinus rhythm was present and no rhythmic disturbances or any other electrocardiographic alterations were observed, and to echocardiographic examination using a Siemens model Sonoline CD apparatus. The diameters of the left ventricle (LV), left atrium, ascending aorta, interventricular septum and posterior wall of the $\mathrm{LV}$, and the ejection fraction of the $L V$ were determined, with values considered to be normal according to pre-established criteria. A dynamic electrocardiogram (24-h Holter monitoring) was obtained using a Dynamis 3000 recorder, with the records being analyzed by the Cardiosystems program, version ALT V5 08C. All 24-h Holter exams were analyzed by a single observer. Cardiac rhythm, heart rate (maximum, minimum and mean) and the presence of cardiac arrhythmias were determined and analyzed with respect to the site of origin (supraventricular and ventricular), frequency and complexity (isolated, polymorphic, coupled, and supraventricular or ventricular tachycardia) when exceeding 50 beats per $24 \mathrm{~h}$, i.e., more than 10 beats per $h$. The presence of atrioventricular and/or intraventricular block and pauses or alterations in the ST segment were also recorded.

The control group consisted of 20 patients aged 16 to 34 years $(22.5 \pm 4.8)$, selected at the Prenatal Outpatient Clinic of HC-UFU, with negative serology for Chagas' disease, asymptomatic in terms of the cardiovascular apparatus, non-smokers, and with electrocardiographic and echocardiographic exams within normal parameters. Dynamic electrocardiography (24-h Holter monitoring) was carried out in both groups between 25 and 30 weeks of gestation.

All patients were again submitted to clinical evaluation, electrocardiography, echocardiography and 24-h dynamic electrocardiography during the second postpartum month. Only one patient from the control group refused to perform the exams. The study was approved by the Medical Ethics Committee of HC-UFU.

Statistical analysis. The nonparametric Wilcoxon test was applied to related variables to compare each group during and after pregnancy. The Mann-Whitney U test was applied to independent variables to compare the two groups during each period analyzed. The Student t-test was used for paired or dependent samples when the complexity of arrhythmias was compared between groups. A P value $<0.05$ was considered to be significant for all tests.

\section{Results}

The mean age of the group of pregnant women with Chagas' disease was 26 years and 11 months $(26.91 \pm 3.6$ years) and the mean age of the control group was 22 years and 6 months ( $22.5 \pm 4.8$ years), with this difference being statistically significant $(\mathrm{P}<0.002)$.

The mean ejection fraction was $74.55 \pm 4.67$ for the chagasic group and $75.5 \pm 4.55$ for the control group, with no significant difference between groups. Twenty-fourhour Holter monitoring was carried out in both groups between 24 and 30 weeks of gestation, with the mean value being $27.75 \pm 1.52$ weeks for the chagasic group and $27.41 \pm$ 1.27 weeks for the control group (not significant). The mean heart rate was $88.8 \pm 10.85 \mathrm{bpm}$ for the chagasic group and $87.85 \pm 6.47 \mathrm{bpm}$ for the control group, with no significant difference between groups.

Table I shows the distribution of the number of premature depolarizationss during and after pregnancy for the chagasic and control groups. During pregnancy, the number of supraventricular premature depolarizations was $6.2 \pm 8.53$ for the chagasic group and $32.1 \pm 103.3$ for the control group, and the mean number of 24 -h ventricular premature depolarizations was $207.7 \pm 839.9$ for the chagasic group and $25.8 \pm 79.27$ for the control group, with no significant difference between groups. After pregnancy, the mean number of supraventricular premature depolarizations was $83.9 \pm 260.4$ for the chagasic group and $7.16 \pm 19$ for the control group. The number of $24-\mathrm{h}$ ventricular premature depolarization was $23.95 \pm 71.02$ for the chagasic group and $118.7 \pm 511.3$ for the control group (not significant).

Table I also shows the number of premature depolarizationss within each group during and after pregnancy. The distribution of the complexity of supraventricular and ventricular arrhythmias during and after pregnancy is shown in table II. Isolated supraventricular premature depolarizations were observed during pregnancy in $18(90 \%)$ patients of both groups and isolated ventricular premature depolarization were observed in $11(55 \%)$ patients of both groups. After pregnancy, isolated supraventricular premature depolarizations predominated in the control group compared to the chagasic group $(\mathrm{P}<0.05)$. Non-sustained tachycardia was only observed in the chagasic group.

\section{Discussion}

Cardiac arrhythmias are events that commonly occur during pregnancy ${ }^{2,7,8}$. More severe cardiac rhythm disturbances, however, are rare. Supraventricular and ventricular premature depolarizationss, chronic sustained or paroxysmal supraventricular tachycardia (atrial flutter, atrial fibrillation, atrial tachycardias, nodal reentrant tachycardia, and $\mathrm{AV}$ reciprocating tachycardia), ventricular tachycardia, dis turbances in electric stimulus conduction, and pre-excitation syndrome have been reported during pregnancy ${ }^{8}$ However, the exact prevalence of each of these arrhythmias is still 


\begin{tabular}{|c|c|c|c|c|c|c|c|c|}
\hline \multirow[b]{3}{*}{ Sample } & \multicolumn{4}{|c|}{ During pregnancy } & \multicolumn{4}{|c|}{ After pregnancy } \\
\hline & \multicolumn{2}{|c|}{ Chagasic group } & \multicolumn{2}{|c|}{ Control group } & \multicolumn{2}{|c|}{ Chagasic group } & \multicolumn{2}{|c|}{ Control group } \\
\hline & SVE & $\mathrm{VE}$ & SVE & VE & SVE & VE & SVE & $\mathrm{VE}$ \\
\hline 1 & 2 & 1 & 2 & 12 & 0 & 0 & 6 & 1 \\
\hline 2 & 8 & 0 & 1 & 0 & 3 & 0 & 1 & 0 \\
\hline 3 & 0 & 0 & 3 & 1 & 0 & 2 & 3 & 0 \\
\hline 4 & 8 & 3757 & 1 & 0 & 3 & 257 & 2 & 0 \\
\hline 5 & 6 & 10 & 6 & 0 & 3 & 3 & 2 & 1 \\
\hline 6 & 3 & 6 & 3 & 0 & 1 & 3 & 0 & 0 \\
\hline 7 & 2 & 0 & 5 & 2 & 5 & 203 & 4 & 1 \\
\hline 8 & 3 & 1 & 6 & 2 & 1143 & 0 & 13 & 6 \\
\hline 9 & 36 & 0 & 3 & 0 & 3 & 6 & 6 & 0 \\
\hline 10 & 2 & 2 & 5 & 63 & 0 & 0 & 3 & 1 \\
\hline 11 & 10 & 357 & 1 & 351 & 9 & 0 & 6 & 0 \\
\hline 12 & 21 & 6 & 4 & 73 & 9 & 0 & 7 & 2 \\
\hline 13 & 2 & 1 & 457 & 0 & 219 & 4 & 0 & 2230 \\
\hline 14 & 0 & 14 & 5 & 0 & 0 & 2 & 18 & 2 \\
\hline 15 & 1 & 0 & 118 & 5 & 2 & 0 & 55 & 10 \\
\hline 16 & 2 & 0 & 5 & 0 & 0 & 0 & 3 & 0 \\
\hline 17 & 9 & 2 & 0 & 4 & 0 & 0 & 4 & 1 \\
\hline 18 & 3 & 0 & 0 & 2 & 6 & 0 & - & - \\
\hline 19 & 2 & 0 & 16 & 1 & 272 & 4 & 2 & 0 \\
\hline 20 & 4 & 9 & 1 & 0 & 0 & 1 & 1 & 0 \\
\hline Mean & 6.2 & 207.7 & 32.1 & 25.8 & 83.9 & 23.95 & 7.16 & 118.3 \\
\hline SD & 8.53 & 838.9 & 103.3 & 9.27 & 206.4 & 71.02 & 19.0 & 511.3 \\
\hline
\end{tabular}

\begin{tabular}{|c|c|c|c|c|c|c|c|c|}
\hline & \multicolumn{4}{|c|}{ Chagasic group $=20$} & \multicolumn{2}{|c|}{ Control group $=20$} & \\
\hline & \multicolumn{2}{|c|}{ Pregnancy } & \multicolumn{2}{|c|}{ After pregnancy } & \multicolumn{2}{|c|}{ Pregnancy } & & After pregnancy \\
\hline & SVE & $\mathrm{VE}$ & SVE & $\mathrm{VE}$ & SVE & $\mathrm{VE}$ & SVE & $\mathrm{VE}$ \\
\hline Isolated & 18 & 11 & $12 *$ & 9 & 18 & 11 & $17 *$ & 11 \\
\hline$>50$ beats $/ 24 \mathrm{~h}$ & 0 & 2 & 3 & 2 & 2 & 3 & 1 & 0 \\
\hline$>10$ beats $/ \mathrm{h}$ & 1 & 2 & 3 & 2 & 2 & 2 & 0 & 1 \\
\hline NST & 1 & 3 & 3 & 0 & 0 & 0 & 1 & 0 \\
\hline Paired & 1 & 1 & 2 & 2 & 2 & 1 & 1 & 0 \\
\hline Polymorphic & 0 & 4 & 0 & 3 & 0 & 6 & 1 & 2 \\
\hline None & 2 & 8 & $7 *$ & 11 & 2 & 9 & $2 *$ & 8 \\
\hline
\end{tabular}

unknown. Some authors have suggested an increase in the frequency of paroxysmal supraventricular tachycardic episodes during pregnancy, with some of the patients experiencing these episodes for the first time ${ }^{9-11}$. Other patients who have a history of arrhythmias before pregnancy show an increase in the frequency, duration and severity of these arrhythmias during pregnancy ${ }^{4}$.

Palpitations, dizziness, presyncope and, eventually, syncope may occur during pregnancy, but the etiology of these manifestations is still unclear. An increase in the incidence of arrhythmias during pregnancy has been reported for patients with and without structural heart disease ${ }^{1-8}$.

Hemodynamic alterations due to volume overload, hormonal changes and influences of the autonomic nervous system increase the incidence of arrhythmias during pregnancy in both women without any evidence o f heart disease and those with established heart disease who do not show any symptoms before pregnancy ${ }^{2,7,12}$. Certain factors such as coffee, tea, smoking, alcohol, nasal decongestants or other toxic drugs can trigger arrhy th mias during pregnancy ${ }^{12-14}$.

Anxiety and elevated estrogen levels lead to adrenergic hyperactivity which, associated with an increased heart rate, alter refractoriness and conduction velocity, predisposing the pregnant women to arrhythmia. The increased physiological blood volume during pregnancy results in an increase in end diastolic pressure of the LV, which in turn increases myocardial stress and therefore also predisposes to arrhythmia $^{2,15,16}$. During anxiety, pregnant women may complain of palpitations due to an increased $p$ erception of heart beats. In which case, sinus tachycardia is commonly recorded and its electrocardiographic clinical correlations can be 
established by performing a resting electrocardiogram or dynamic electrocardiography (24-h Holter monitoring).

Modifications in electric stimulus conduction in the atria and ventricles, as well as in tissue refractory periods that are altered from modulations by circulating catecholamines, may predispose to the occurrence of arrhythmias due to a reentry mechanism ${ }^{17,18}$. The incidence of these arrhythmias during pregnancy is variable, and is accompanied by palpitations due to premature depolarizationss and benign tachyarrhythmias which are usually well tolerated from a clinical point of view ${ }^{2,17}$.

Investigations on cardiac arrhythmias during pregnancy in patients with the so-called indeterminate form of Chagas' disease, as well as studies on the prevalence of cardiacrhythm disturbances in men and non-pregnant women, are scarce. Pereira Barreto et a ${ }^{19}$ studied 22 patients with the indeterminate form of Chagas' disease by 24-h dynamic electrocardiography to determine the incidence and importance of ventricular arrhythmias. The authors observed arrhythmias in $14(63.6 \%)$ of the patients, with $11(50 \%)$ patients showing ventricular premature depolarizationss of the isolated, bigeminal and polymorphic type, and $4(18.2 \%)$ patients showing supraventricular premature depolarizations.

Marins el $\mathrm{al}^{6}$ found a $42.5 \%$ prevalence of arrhythmias determined by $24-\mathrm{h}$ Holter monitoring, with $27.2 \%$ of the patients presenting ventricular arrhythmias, and $8(24.0 \%)$ patients presenting arrhythmias considered by the authors to be of high risk (premature depolarizationss in bursts or bigeminal and trigeminal premature depolarizationss, and ventricular tachycardia). Almeida et al ${ }^{20}$, comparing 15 patients with the indeterminate form of the disease to a control group, demonstrated an elevated prevalence of isolated ventricular premature depolarizationss.

Rassi et al ${ }^{21}$, determining the frequency and extent of ventricular premature depolarizationss in 103 patients with the indeterminate form of Chagas' disease and 20 control patients, observed a slightly higher incidence of ventricular arrhythmias in the control group ( $85 v s 74 \%$ ). The authors concluded that patients with the indeterminate form of Chagas' disease do not behave differently from the normal population.

In the present study, 18 (90\%) chagasic pregnant women and 18 control patients presented supraventricular premature depolarizations and $11(55 \%)$ patients presented ventricular premature depolarization. After pregnancy (two months after delivery), a predominance of supraventricular premature depolarizations was observed in the control group compared to the chagasic group (Table II). No signifi- cant difference in the number of supraventricular premature depolarizations or ventricular premature depolarization during pregnancy was observed between groups (Table I), despite a larger mean number of ventricular premature depolarization in the chagasic group compared to the control group. Twenty-four-hour Holter monitoring carried out during the postpartum period also did not show a significant difference between groups.

Shotan et al ${ }^{1}$, comparing 52 asymptomatic heart disease pregnant patients with 110 pregnant women without heart disease symptoms of palpitations, dizziness, presyncope and syncope, observed a $58 \%$ rate of supraventricular premature depolarizations in the asymptomatic group and a $56 \%$ rate in the symptomatic group upon 24 -h dynamic electrocardiography, while ventricular premature depolarization were observed in $40 \%$ of the asymptomatic pregnant patients and in $49 \%$ of the symptomatic patients, this difference was not nonsignificant. Only nine patients were studied by $24-\mathrm{h}$ Holter monitoring during the postpartum period and the authors did not report the number of premature depolarizations or the number of women with arrhythmias, although they observed a tendency towards a reduction in arrhythmias during pregnancy. The authors also observed only a weak correlation between the incidence of arrhythmias and the presence of symptoms, with only $10 \%$ of symptomatic episodes being accompanied by arrhythmias.

Ovando et al ${ }^{22}$, studying 47 pregnant patients by $24-\mathrm{h}$ Holter monitoring during labor (before, during and after delivery), found a $72.3 \%$ prevalence of arrhythmias, with supraventricular arrhythmias being the most frequent form and with the incidence of these arrhythmias being the same before and after delivery. Ventricular arrhythmias were reported in $14(41.1 \%)$ patients, and mainly occurred in the form of monomorphic and polymorphic ventricular premature depolarization which, in some cases, showed relatively severe characteristics.

The results of the present study with respect to the number and complexity of supraventricular premature depolarizations and ventricular premature depolarization agree with those obtained by Shotan ${ }^{1}$ and Ovando ${ }^{22}$ in normal pregnancies. However, it is important to emphasize that there are no studies using 24-h Holter monitoring in Chagas' disease without apparent heart disease.

A comparison of our results with data available in the literature led us to conclude that the presence of cardiac rhythm disturbances in chagasic or non-chagasic patients during pregnancy does not seem to be of clinical importance.

\section{References}

1. Shotan A, Ostrzega E, Mehra A, Johnson JV, Elkayan U. Incidence of arrhythmias in normal, pregnancy and relation to palpitations, dizziness, and syncope. Am J Cardiol 1997; 79: 1061-4.

2. Blanco VMR, Álvares VB. Tratamiento de las arritmias cardiacas durante el embarazo. Med Clin (Barc) 1996; 107: 29-36.

3. Hair TE, Eagan JT, Orgain ES. Paroxysmal ventricular tachycardia in the absence of demonstrable heart disease. Am J Cardiol 1962; 9: 209-14.
4. Brodsky M, Doria R, Allen B, Sato D, Thomas G, Sada M. New onset ventricular tachycardia during pregnancy. Am Heart J 1992; 123: 933-41

5. Sobotka PA, Mayer JH, Bauernfeind RA, Kanakis C Jr, Rosen KM. Arrhythmias documented by 24-hour continuous ambulatory eletrocardiographic monitoring in young women with out apparent heart disease. Am Heart J 1981; 101: 573-9.

6. Marins N, Flores AP, Seixas TN, et al. Eletrocardiografia dinâmica em chagásicosna formaindeterminadaou sem cardiopatiaaparente. ArqBras Cardiol 1982;39:303-07. 
7. Elkayan U, Gleicher N. Cardiac arrithythmias and pregnancy: cardiac problems in pregnancy. Wiley-Liss. A John Wiley \& Sons Inc., Publication, 1998; 761p: $155-174 \mathrm{p}$.

8. Mendelson CL. Disorder of heart beat during pregnancy. Am J Obstet Gynecol 1956; $72: 1268-301$

9. Lee SH, Chen SA, Wu TJ, et al. Effect of pregnancy on first onset and symptoms of paroxysmal supraventricular tachycardia. Am J Cardiol 1995; 76: 675-8.

10. Tawan M, Levine J, Mendelson M, Goldberger J, Dyer A, Hadish A. Effect of pregnancy on paroxysmal supraventricular tachycardia. Am J Cardiol 1993; 72: 838-40.

11. Szekely P, Snaith L. Paroxysmal tachycardia in pregnancy. Br Heart J 1953; 15 : 195-8.

12. Moreira DAR. Arritmias na gravidez. Rev Soc Cardiol Estado de São Paulo 1994; 6:552-9.

13. Hensleigh PA, Brown EL. Psychosocial stress and pregnancy. In: Gleicher N, ed. Principles of Medical Terapy in Pregnancy. New York: Plenum Medical Book Co. 1985: 885-8

14. Barron WM, Mujais SK, Zinaman M, Bravo EL, Lindheimer MD. Plasma catecholamine responses to physiologic stimuli in normal human pregnancy. Am J Obstet Gynecol 1986; 154:80-84
15. Cole PL, Sutton MSJ. Normal cardiopulmonary adjustments to pregnancy cardiovascular evaluation. Cardiovasc Clin 1989; 19:37-56.

16. Barriales V, Martinez TI. Cardiopatia y embarazo. Med Clin (Barc) 1990; 94 : $389-95$

17. Moreira DAR. Arritmias em gestantes. Rev Soc Cardiol Estado de São Paulo $1998 ; 1 ; 127-36$

18. Louhana G. The electrical activity of the heart during pregnancy. Rev Fr Gynecol Obstet 1990; 85:369-74.

19. Pereira Barretto AC, Bellotti G, Sosa E, et al. Arritmias e a forma indeterminada da doença de Chagas. Arq Bras Cardiol 1986; 47: 197-99.

20. Almeida JWR, Shikanai MAY, Amato Neto V, Catilho EA, Barretto ACP. Estudo da forma indeterminada da doença de Chagas através da eletrocardiografia dinâmica. Rev Inst Med Trop São Paulo 1982; 24: 222-8

21. Rassi Jr. A, Rassi AG, Rassi SG, Rassi Jr. L, Rassi A. Freqüência e grau da extra-sistolia ventricular à eletrocardiografia dinâmica (sistema Holter de 24 horas) na doença de Chagas. Arq Bras Cardiol 1991; 57(supl C): C146.

22. Ovando AL, Germiniani H, Miglino R, da Cunha GP. Estudo das arritmias cardíacas maternas durante o trabalho de parto e o parto. Arq Bras Cardiol 1983;40: $171-6$

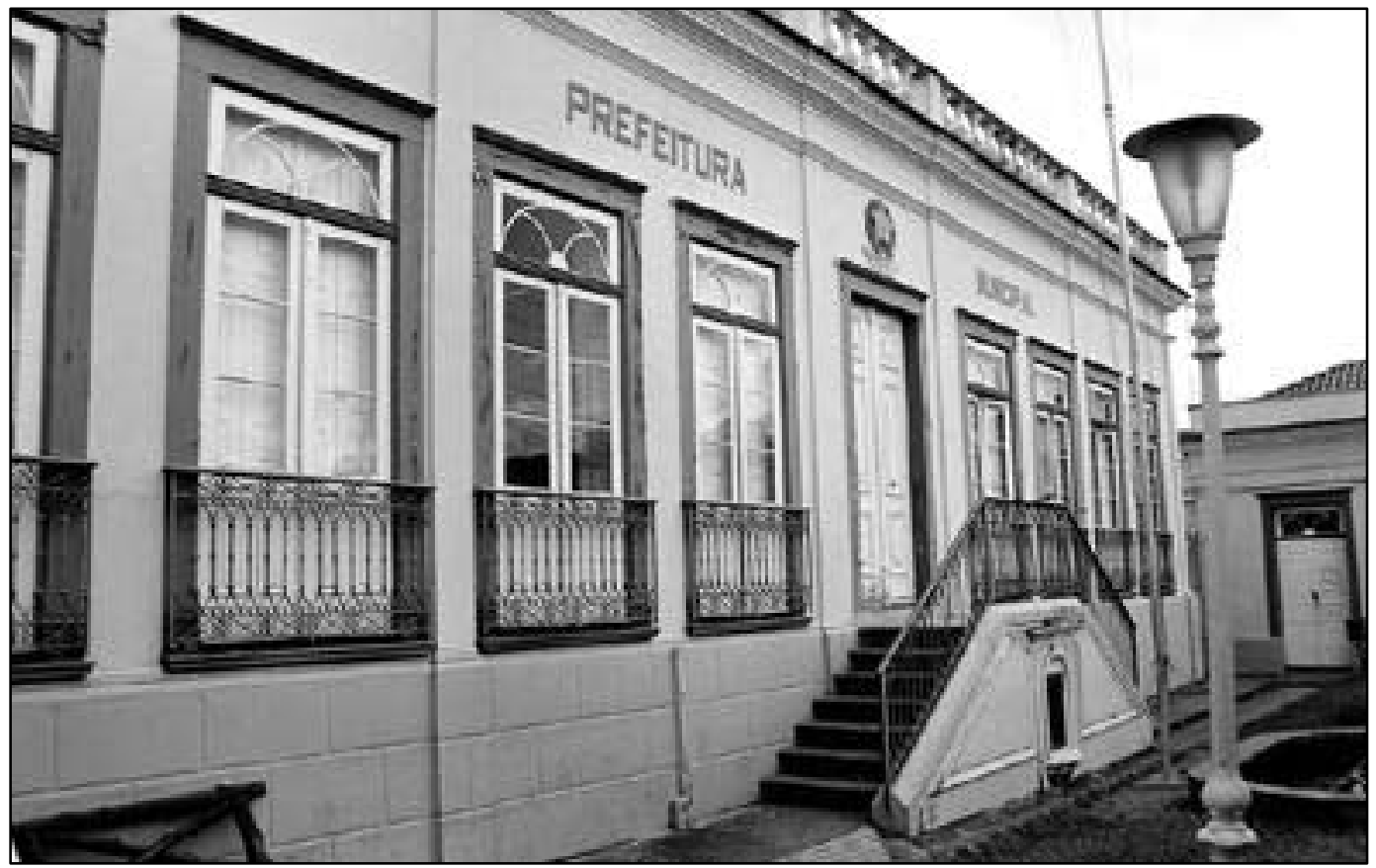

Prefeitura Municipal de Leopoldina - MG

César Grupi, André Alves

Editor da Seção de Fotografias Artísticas: Cícero Piva de Albuquerque

Correspondência: InCor - Av. Dr. Enéas C. Aguiar, 44 - 05403-000 - São Paulo, SP - E-mail: delcicero@incor. usp.br 